\title{
On the Translation of Long and Complex English Sentences
}

\author{
Juan Zou \\ Foreign Language Department, Hubei University, Wuhan, China \\ Email address: \\ 1183647623@qq.com \\ To cite this article: \\ Juan Zou. On the Translation of Long and Complex English Sentences. International Journal of Language and Linguistics. \\ Vol. 4, No. 6, 2016, pp. 190-197. doi: 10.11648/j.ij11.20160406.11
}

Received: August 16, 2016; Accepted: September 18, 2016; Published: October 13, 2016

\begin{abstract}
Since the 1st century AD the translation of Buddhist in China and from the ancient Greece the translation of Bible, a host of masters have published wisdoms and insights on translation according to their practical experience of translating. Various kinds of translation theory such as Eugene Nada's functional equivalence theory, skopos theory and so on has come out. But a complete work on the analysis of long and complex English translation is very few. Until the early years of 20 century when translation has been defined as a subject of science, long and difficult English sentence began to go into the research scope of scholars. Besides, as it known to all translators, sentence is the ideal unit for English-Chinese translation. Meanwhile, long and complex sentence claims to be the key and most difficult one. Therefore, it is of great necessity for translation workers, especially for the beginners to make a research on the translation of long and complex English sentence. The research on this field is not only a theoretical research with strong practical use but also be of great importance to the comparative analysis of words and phrases between Chinese and English in a macro level. It can also enhance translators to make new breakthroughs in their translation career, which may better cultural exchange among countries and bring more accurate masterpiece for the world. Hence, this paper intends to start from the entry point of the characteristics of long complex English sentences, and then do a in-depths analysis on the reason of translating difficulties further, through which the author hopes that the reader can get a clear understanding of the impact on the user's thinking style made by different language and the difference in phrases and sentence structures of diverse language family. Thus, all the learner learn it and memorized it by heart. In the end, the author is, through her continuous practice and paint experience, willing to conclude a more clear steps and methods of translation. Last but not least, what matters to the ability of translation is rely on the translator's persistent hardworking. All the translation work lovers should better make further efforts under the instruction of correct theory direction.
\end{abstract}

Keywords: Translation Theory, Long and Complex Sentence, Thinking Patterns

\section{Introduction}

English-Chinese translation is a course of converting the information from English into Chinese correctly, smoothly and coherently. Logically it consists of two stages: receive, understand the meaning of the source language-English, and rearrange it into target language-Chinese. [1] This process requires that the translator possessed a sound knowledge of linguistics, semantics and language user's cultures.

Due to the intrinsic difference between English and Chinese, the long English sentence, more often than not, poses a problem for English-Chinese translation. How to translate long English sentences has become a classic topic in translation study. In the light of this problem, this thesis will discuss the translation of long complex English sentences, which the author hope can be helpful to the translators.

First, what are long sentences? According to the previous research into this issue, some scholars claim that a sentences with a certain amount of words can be defied as a long sentences, but in English, a long sentence can contains as many as over 100 words while some long sentence may has only 40words in it. [2] Anyway, it's still long. So the length of a sentence can not be the only criterion to decide if a sentence is a long sentence.

Besides, what makes a long English sentence difficult to translate is the fact that Chinese and English have different thinking habits, which naturally leads to their difference in ways of expression and sentence structure. Thus the emphasis of this essay is to give a comparison between the structures of English and Chinese sentences. The reasons are also discussed. The priority of this essay is given to the steps, 
which should be taken, and the methods employed in long sentence translation and vice versa.

Before the research of long complex English sentences, we should better firstly take a look at the definition and nature of translation.

The Oxford English dictionary makes it as to turn from one language into another. [3]

Translation is a kind of cross-linguistic, cross-culture and cross-social communication.

Translation means conversion of an expression from one language into another. To say it plainly, translation is an art to reproduce the exact idea of the author by means of a language different from the original.

Translating consists in reproducing in the receptor language the closest natural equivalent of the source language messages, first in terms of meaning and secondly in terms of style. [4]

"Translation serves as a means of communication, a transmitter of culture, a technique of language learning, and a source of personal pleasure. It has the special purpose of demonstrating the learner's knowledge of foreign language. [5]

Translation is a science, an art, a skill, a craft, an operation or a kind of communication.

Among them the first two may be the most influential and controversial, which evolve into two never-compromising schools in the field of translation.

If "translation" refers to a subject, namely, the study of translation theory and skills, it is no doubt a science with its own rules, laws and principles for the translator to abide by;

If it refers to some specific pieces of translation, then it is more like an art, with each piece manifesting its own charms and style in the creative hands of the translator;

If it refers to a process, then we may regard it as a craft or skill. For unlike any branch of natural science, the process of translation has its peculiarity, and none of its rules and principles is universally applicable. [6]

To be more precise, translation is both an art and a science and deserves all the translator's appreciation and research. Secondly, the author should better figure out two kinds of relationship which is of great importance to the understanding of this thesis. One is the relation of translation theory and its practice, the other is the relation between culture and language.

When talking about translation theory and practice, a famous American scholar Hemoles give his perspective in the book the name and nature of translation studies, "in a broader sense, the ultimate goal of a translation theorist is definitely to establish an adequate and comprehensive theory, contain enough components to explain and predict the phenomenon related to translation pieces. Apart from guidance, translation theory also worked as description and expounds, inspire and forecast practice. Therefore, certain knowledge of translation theory is a must for translators and interpreters." [7]

As translation is the conversion or transfer of two different languages, it is no doubt involved with culture. Language is closely connected with culture; likewise, meaning is closely connected with culture.

\section{Comprehension of Long Complex English Sentences}

\subsection{Definition of Long Complex English Sentences}

Generally, long and complex sentences refer to the sentences which are long and complex. To be exactly, long sentences always contain as many as 100 words, while complex sentences may only with 40 words. Later, a new theory that a sentence with two or more clauses or sub-clauses and around 20 words or above is a long sentence came into being, which won a wide approval. Long sentence is classified into three categories: the first is paralleling long sentence, which consists of two or more clauses with complete sentence structure and without affiliation; the second is compound long sentence, which comprises a principle clause and some other sub-clauses like noun clauses, attributive clauses, adverbial clause, etc; and the last is paralleling and compound long sentence, which as the name implies, the most complicated with the features of the previous two types of long sentences. [8] In a nutshell, long sentence are characterized by frequent use of attributive and adverbial clauses, compound structures and parenthesis.

Actually, long and complex English sentence is made up of plenty of clauses and the relationship of those clauses may include embedding, nesting and paralleling. Thus, the translation of long sentences is virtually on the translation of all the clauses and their relationship. Functionally, there are three kinds of compound sentences: first, substantive clauses consist of subject clauses, object clauses, predictive clauses and appositive clauses; Secondly, adjective clause that is attributive clauses; the last one is adverbial clauses. [9]

\subsection{Features of Long Complex Sentences}

What is the character and analyzing method of long and complex English sentences? Compound sentence is the one that cover several kinds of grammatical relationship and special sentence structure. English is famous for its long sentences, because English sentences may come with postpositive attributive and some extended one can be a compound sentence with clauses and long modifier. These sentences are always featured by complicated structure, strict logicality. [10] But, no matter how long a sentence may be, how intricate the structure may be, they are composed by some basic components. As long as the translators button down the sentence structure of source text, seek out the main idea and other meanings of them, and then give an analysis of the logic relationship between all clauses, he/she can crack the hard nut easily.

Through a long time observation and careful deliberation, the author may conclude the characteristics of long and complex English sentences as follows,

Complicated in structure and multiple levels of logic.

The extended meanings of words on the basis of context. 
Judge on the referential relationship of reference words with reference to the content.

A large numbers of coordinative constituents.

Numerous modifier, especially for the long postpositive attributive.

Collocations and idioms. [11]

To illustrate, the author give an analysis of long and complex English sentences appeared in the GRE examination and Chinese postgraduate English examination.

Example: That sex ration will be favored which maximize the number of descendants an individual will have and hence the number of gene copies transmitted.

This is an inverted sentence. So it should be recovered into its normal word order.

That sex ratio which maximizes the number of descendants that an individual will have and hence the sex ration which maximize the number of gene copies transmitted will be favored.

Example: The methods that a community devises to perpetuate itself come into being to preserve aspects of the cultural legacy that that community perceives as essential.

This is a sentence with complicated modifiers, including, clauses, prepositional phrase, participle and infinitive. Sometimes, these modifiers appeared more than once in only one sentence. When reading we should first read out its subject: the methods, verb: come into being, and object: adverbial clause of purpose, namely the trunk of the sentence. The correct transcript is:一个社会设计出来保存自己的方 法得以形成来保持那个社会认为最重要的一些方面. [12]

\section{Reason analysis of Difficulties in Translating Long and Complex English Sentences}

\subsection{Comparison of Chinese and English Thinking Style}

When doing translation, the translators may found that many factors such as culture, thinking style and language will make an influence on it. Among all, the disparity in thinking style claims to be the most distinct one. [13] This section will mainly focus on the comparison of different thinking patterns between Chinese and American. And also figure out the reason behind such disparity being produced. The purpose is to make it clear of the difficulties in the conversion of two languages, avoid some basic mistakes and misunderstandings, so as to provide better transcripts and enhance fluent communication.

The disparity has displayed in a sorts of aspect. Firstly, Chinese emphasis on image thinking, while American put importance on abstract thinking in terms of the thinking structure. The people who apply image thinking always based on their experience, through the link with others to develop interpersonal relation. Image thinking is featured with the thinking pattern like analogy, metaphor and simplify. [14]

Abstract thinking always called logic thinking.
English language is more care with structure, and Chinese value semantics. Once a famous Chinese linguistics wangli has said that: "in terms of the sentence structure, western language is ruled by law while Chinese language is ruled by man." [15]

For instance, children will play with dolls equipped with personality chips, computers with inbuilt personalities will be regarded as workmates rather than tools, relaxation will be in front of smell television, and digital age will have arrived.

Transcripts: 儿童将与装有个性芯片的玩具娃娃玩夏, 具 有个性内置的计算机将被视为工作伙伴而不是工具, 人们 将在气味电视前休闲, 到这时数字时代就来到了.

This is a compound sentence made up of four independent clauses. The first three sentences used future tense and the last one is future perfect sentence. The relationship between sentences is showed through tense, comma and coordinating conjunction. However, the Chinese transcript is expressed more concisely and the relationship between sentences is reflected through semantics. The first three sentences can be seen as coordinative relation and the last one indicates the results.

\subsection{Comparison Between Chinese and English}

As what stated above, Chinese belongs to the Sino-Tibetan Family, and English belongs to the Indo-European Family. Chinese is one of the oldest languages in the world, and English is the most widely used language in the world. They are both the official language employed in the United Nations. Besides, these two languages posses some similarities in words like polysemy, semantic fuzziness and word-formation like synthesis method, affixation. The main components of a sentence include subject, verb and object. Likewise, the figure of speech like metaphor, simile and metonymy are used in writing. However, as they belong to different language family, each formed its own cultural tradition, the difference is self-evident.

English is full of changes and Chinese is full of repetition.

The monkey's most extraordinary accomplishment was learning to operate a tractor. By the age of nine, the monkey had learned to solo on the vehicle.

Transcripts: 这只猴子最了不起的成就是学会驾驶拖拉 机.到九岁的时候, 这只猴子已经学会了单独表演驾驶拖 拉机了.

Obviously, the meaning of tractor is the same with vehicle. When in Chinese they were identical matter, but expressed in different words in English

For people who practice more may get to know that the difficulties of English translation lie not only in the complex structure, but also in the abstract expression. Through elaborate analysis, long sentence and subordinate clauses can be changed to short sentence and sub-clause. The problem of structure can be smoothly done and readily solved. But when encountered with abstract expression, the translator must have a thorough grasp of the original meaning and then make a specific output in Chinese, which is a real challenge to translators.

For instance, 
disintegration 土崩瓦解

ardent loyalty 赤胆忠心

Total exhaustion 筋疲力尽

far-sightedness 远见卓识

Careful consideration 深思熟虑

perfect harmony 水乳交融

Feed on fancies 画饼充饥

with great eagerness 如饥似渴

Lack of perseverance 三天打鱼, 两天晒网

Make a litter contribution (捐款; 捐助) 添砖加瓦

On the verge of destruction 危在旦夕

And another example,

Until such time as mankind has the sense to lower its population to the points whereas the planet can provide a comfortable support for all, people will have to accept more "unnatural food".

Transcripts: 除非人类终于意识到要把人口减少到这样 的程度: 使地球能为所有人提供足够的饮食, 否则人们将 不得不接受更多的“人造食品”。

There are three abstract nouns and two abstract adjectives in the original sentence respectively. According to the explanation offered by the syllabus, the word "sense" means 感觉, 判断力; point means 点; support means 支撑 物，支持物; and comfortable means 舒适的; unnatural means 非自然的. All these words are with abstract meaning. If we translate it in a literal way without deep understanding, the transcripts may be the following.

The meaning of a specific English word is known by extension, but in Chinese it depends on reasoning. There are two popular saying in English, namely, "you know a word by the company it keeps." And "words do not have meaning, but people have meaning for them." This demonstrates that the definition and interpretation of a word given by dictionary is dead. Nevertheless, language, in practical application is flexible. And it is the extension of words meaning and usage that makes this flexible application possible. When translating, translator must comprehend this extension through illation.

For example, while there are almost as many definitions of history as there are historians, modern practice most closely conforms to one that sees history as the attempt to recreate and explain the significant events of the past.

Transcripts: 尽管关于历史的定义几乎和历史学家一样 多, 现代实践最符合这样一种定义, 即把历史看作是对过 去重大历史事件的再现和解释.

Through word-formation and interpretation on common dictionary, the meaning of "recreate" is to create again. Besides, in the syllabus of word list only the noun form recreation is defined as entertainment. In this case, we may easily translate recreate into re-invent or amusement. However, if analyzed closely you can find that the word recreate is carried with object of "the significant evens of the past." Logically, history can not create again. Therefore its meaning needs extending. Usually translate workers may feel ignorant to express the word you are familiar to, because words need extension and inference. [16]

\section{Steps and Methods of Translating Long Complex English Sentences}

\subsection{Steps in Translating Long Complex English Sentences}

Actually, numerous approaches have been purposed through the course of translation development by academicians. Such as the three steps in translation process by Nida, structural analysis approach by Peter Newmark, translation method based on the difference of English and Chinese and the recently popular one of understanding, expression and revising.

The three steps in translation process raised in 1969 by Nida include analysis, transformation and restructuring. The first step analysis refers to obtain its in-depth meaning or connotative cultural meaning through analysis on the surface or grammatical structure of original sentence. And the in-depth meaning will be expressed in a core sentence, that is, translator must write out core sentence in original language through his own analysis and understanding. Generally, core sentence are the simple declarative sentence with active voice. In the perspective of Nida, core sentence are the fundamental elements in constructing an intricate sentence complex as well as the basic units for translator to operate. The second step transformation means to transfer the core sentence of source language to target language, thus finishing the deliver of in-depth meaning from original text to translation. And the last step is to rewrite the core sentence in accordance with the criterion of target language, making it a faithful and expressive version. [17]

In current teaching material, students may see a relatively popular method based on the difference of English and Chinese. It also consists of three steps: to read and comprehend the original sentence first, then find the branches of sentence, like the trunk of a tree and sort out the structure, third step is to comprehensively utilize the techniques of split and combination, sequence adjust-ion, conversion of part of speech and so on to reorder the sentence so as to tally with the standard of target language and the final one is produce translation on the basis of the third step. However, every theory or method has its advantages and disadvantages. The author anticipates that both advantages should be learned and adopted.

Therefore, when encountered with a long and complex sentence, the first step is to make a comprehensive and thorough understanding of the original meaning. At the same time, express the main idea or we may say the core sentence in both source language and target language.

The second step is to find out the trunk of sentence which usually contains subject, verb and object. Besides, all the other sentence constitutes should be sorted out, such as various kinds of clauses, modifiers, parentheses, prepositional phrase etc. what is more, the logic relationship between the predicate and the rest of components.

Then, draw a general draft of translation but make sure the logic relation and modifiers of words are with no mistake. And in the light of the norm of source language, make tiny 
adjustments of its grammar and order to meets translation standard.

Last step is to revise. Make a comparison of your transcripts with the core sentence to see if there exists any divergence or difference.

Let us see an example together.

The progress to the statute book of the necessary legal infrastructure for the electronic commerce has in many countries been delayed by a difficult and politically sensitive debate created by the concerns of law enforcement authorities that the widespread use of strong encryption may facilitate crime and terrorism to a degree that will destabilize civilized governments.

First, understanding of the sentence includes new word like encryption, main idea that is a progress was delayed by a debate which results from a concern. in Chinese, it is 由一场 担忧引起的辩论延误了某个过程. Second to start from the structure, the main clause is the progress was delayed respectively representing subject and predicate. And the rest of ingredients: preposition structure, adverbial of place, adverbial of reason clause, appositive clause and attributive clause, Namely to the statute book of the necessary legal infrastructure for electronic commerce, 必要的电子商务法 律归入法典 in many countries 在很多国家 by a difficult and politically sensitive debate, 由于一场难以解决的政治上 敏感的辩论 concerns of law enforcement authorities, 执法机 关的担忧 the widespread use of strong encryption may facilitate crime and terrorism,严格加密的广泛使用会给犯 罪分子和恐怖活动提供方便 that will destabilize civilized governments. 破坏文明政府的稳定

Then we can reorganize a translation that serves to Chinese word order and revise it.

在许多国家, 执法机关担心严格加密的使用, 会给犯罪 分子和恐怖活动提供方便, 从而破坏文明政府的稳定. 这 种担心引起了一场难以解决的, 政治上敏感的辩论. 而这 场辩论则延误了必要的电子商务法律归入法典的过程

\subsection{Methods in Translating Long Complex Sentences}

English is a language of variety with many kinds of clauses and structures. To be more precisely, the translation of noun clauses, attributive clauses, adverbial clauses, passive voice, negative structure, comparative structure, emphatic structure and parenthesis structure. It may to some degree a little trivial to touch upon the translation techniques of every structure. But generally the following three methods are taken in translation.

One. Order method. When the narration arrangements of the content of long English sentence are consistent with Chinese basically, we can translate the sentence into Chinese according to the order of English original text. This occasion occurs frequently in subject clause, object clauses, predicative clause and appositive clause. [18]

Example: Even when we turn off the beside lamp and are fast asleep, electricity is working for us, driving our refrigerators, heating our water, or keeping our rooms air-conditioned.

Analysis: this sentence is made up of a main clause, three present participles served as incidental adverbial modifiers and a time adverbial clause, which is in the head of the sentence. there are some meanings from five aspects: Even when we turn off the beside lamp and are fast asleep, electricity is working for us, driving our refrigerators, heating our water, or keeping our rooms air-conditioned. The logistic relationship among them and the order of expression go all the way with Chinese, therefore, we can use order method to translate the sentence into Chinese as: 即使在我们关掉了床 头灯深深地进入梦乡时, 电仍在为我们工作; 帮我们开动 电冰箱, 把水加热, 或使室内空调机继续运转.

Example: But now it is realized that suppliers of some of them are limited, and it is even possible to give a reasonable estimate of their "expectation of life" the time it will take to exhaust all known sources and reserves of these materials.

Analysis: The main structure of this sentence is "It is realized that...", "it" is the modal subject, "that" guides the subject clause and its paratactic structure "it is even possible to...", in which the infinitive phrases serve as the subject, "the time" is the apposition of "expectation of life", we can further explain its meaning, but the sentence behind the word "time" is its attributive clause. And the five predicate structures express the meaning from four aspects: but now it is realized that; supplies of some of them are limited; it is even possible to give a reasonable estimate of their "expectation of life"; the time it will take to exhaust all known sources and reserves of these materials.

According to the methods of translation, we can make an adjustment to the fourth one, then the version can be: 可是 现在人们意识到, 其中有些矿物质的蕴藏量是有限的, 人 们甚至还可以比较合理的估计出这些矿物质 “可望存在多 少年”, 也就是说, 经过若干年后, 这些矿物的全部已知矿 源和储量将消耗殆尽.

Example: Prior to the twentieth century, women in novels were stereotypes of lacking any features that made them unique individuals and were also subject to numerous restrictions imposed by male-dominated culture.

As what talked about above, we can translate this sentence into: 在 20 世纪以前, 小说中的妇女像都是一个模式.她们 没有任何特点, 因而无法成为具有个性的人; 他们还要屈 从于由男性主宰的文化传统强加给他们的种种束缚.

Two. Reverse order. Some lengthy English sentences have different norms of expression from Chinese, even differ entirely, and then we have to start from the back of the original text to translate. [18]

Example: Aluminum remained unknown until the nineteenth century, because nowhere in nature is it found free, owing to its always being combined with other elements, most commonly with oxygen, for which it has a strong affinity.

Analysis: This sentence is made up of a main clause, two reason adverbial modifiers and an attributive clause, "Aluminum remained unknown until the nineteenth century" is the main clause and it is also the center point of the whole sentence, there are four pieces of predicate structure in all which contains meaning from five aspects: aluminum remained unknown until the nineteenth century; because 
nowhere in nature is it found free; owing to its always being combined with other elements; most commonly with oxygen; it has a strong affinity.

According to the norms of Chinese expression, the reason is always prior to the result, thus we can go against the order of the original text and translate this sentence into: 铝总是跟 其他元素结合在一起, 最普遍的是跟氧有很强的亲和力, 由于这个原因, 在自然界找不到游离状态的铝. 所以, 铝 直到 19 世纪才被人发现.

Example: It therefore becomes more and more important that, if students are not to waste their opportunities, there will have to be much more detailed information about courses and more advice.

Analysis: This sentence is composed of a main clause, an adverbial clause for condition and an object clause. "...becomes more and more important" is the main clause, and it is also the center point of the whole sentence, the three pieces of predicate structure contain three aspects of meanings:...becomes more and more important; if students are not to waste their opportunities; there will have to be much more detailed information about courses and more advice. In order to make the version congruous with the norms of Chinese expression, the author also adopt the reverse order and translate this sentence into: 因此, 如果要 使学生充分利用他们 (上大学) 的机会, 就得为他们提供 大量关于课程的更为详尽的信息，作更多的指导.这个问 题显得越来越重要了.

Example: It is probably easier for teachers than for students to appreciate the reasons why learning English seems to become increasingly difficult once the basic structures and patterns of the language have been understood.

This sentence can be translated into: 一旦了解英语的基 本结构和句型, 再往下学似乎就越来越难了, 这其中的原 因, 也许教师比学生更容易理解.

Three. Detaching sentences. Sometimes the subject or the principal clause has no close relationship with the modifiers in the long English sentences. When translating we can accord with the norms of Chinese-more short sentences into short one, and narrate separately. [18] In order to make the meaning of the text coherent, sometimes some words need to be added.

Example: The number of the young people in the United States who cannot read is incredible about one in four.

Analysis: The sentence mentioned above is a relatively easy one in English, but if we translate it in accordance with the sentence structure of the original text, the sentence is probably translated as: 没有阅读能力的美国青年人的数目 令人难以相信约为 $1 / 4$. Thus, the version is extremely inflowing, and it does not accord with the norms of Chinese. Therefore, we can translate this sentence as: 大约 1/4 的美国 青年人没有阅读能力, 这简直令人难以置信.

Example: Television, it is often said, keeps one informed about current events, allows one to follow the latest developments in science and politics, and offers an endless series of programmers which are both instructive and entertaining.

Analysis: In this long sentence, there is a parenthesis "it is often said" , three pieces of predicate structure, as well as an attributive clause. Seeing from the structure, the three pieces of predicate structure belong to one sentence, but they all have absolute meanings, therefore, when translating translators can use the third method-detaching sentences, then translators can detach the whole sentence into several short ones according to the norms of Chinese expression.

Then the version can be: 人们常说, 通过电视可以了解 时事, 掌握科学和政治的最新动态. 从电视里还可以看到 层出不穷、既有教育意义又有娱乐性的节目.

Example: All they have to do is pressing a button, and they can see plays, films, operas, and shows of every kind, not to mention political discussions and the latest exciting football match.

The version is: 他们所必须做的只是按一下开关.开关一 开, 就可以看到电视剧、电影、歌剧, 以及其他各种各样 的文艺节目.至于政治问题的辩论、最近的激动人心的足 球比赛更是不在话下.

Four. Integration method. We have talked about three kinds of methods to translate lengthy English sentences into Chinese, such as: the order method, the reverse order law and detaching sentences. In fact, when translating translators do not use only one kind of method, but to integrate all kinds of methods together, which has been shown in the sentences mentioned above. Especially in the following situations, if translators just use one of the methods they cannot do the translation work well, so it needs careful analysis. In the light of the priority of time, or in term of logical order, translators can carry on synthesis processing on the whole sentence, and then they can translate the English original text into smooth and faithful Chinese sentences.

Example: People were afraid to leave their houses, for although the police had been ordered to standby in case of emergency; they were just as confused and helpless as anybody else.

Analysis: This sentence has some meanings from three layers as followed: people were afraid to leave their house; although the police had been ordered to standby in case of emergency; they were just as confused and helpless as anybody else. In the three layers of meaning, the second layer stands for concession, the third one stands for reason, while the first layer stands for result, we can make an arrangement as followings according to the norms of Chinese expression as: 尽管警察已经接到命令, 要做好准备以应付紧急情况, 但人们不敢出门, 因为警察也和其他人一样不知所措和无 能为力.

Next, let' s see more examples:

Example: Modern scientific and technical books, especially textbooks, require revision at short intervals if their authors wish to keep pace with new ideas, observations and discoveries. 对于现代书籍, 特别是对于教科书来说, 要是作者希望自己书中的内容能与新概念、新观察到的事 实和新发现同步发展的话, 那么就应该每隔较短的时间将 书中的内容重新修改.

Example: Taking his cue from Ibsen's A Doll' s House, in which the heroine, Nora, leaves home, because she resents her husband' s treating her like a child, the writer Lu Xun 
warned that Nora would need money to support herself; she must have economic rights to survive. 易卜生的剧作《玩偶 之家》中的女主人公娜拉离家出走, 因为憎恶她的丈夫像 孩子一样对待她.作家鲁迅从中得到启示，从而告诫人们 娜拉得需要钱来养活自己, 她要生存就必须有经济上的权 利.

\section{Conclusion}

The long complex English sentence plays a very important role in translation, so more attention should be paid to it. This thesis starts with the definition of long complex sentence, then it talks about the features of long English sentences to get a general understanding of the long English sentences, especially the various kinds of clauses. As we all know, the English sentences tends to be longer and more complicated than the Chinese sentences, the main reason lies in that English and Chinese belongs to different families, so in part there the author mainly analyze the difference between the two, from both language and thinking pattern as well as culture. First we should know the difference of our thinking style which also is the source of our language difference. All the language disparity, involving words sentence semantics structure and grammar are the reflection of our difference in brain movement. Then proceeding from the reason, based on the techniques and methods by our senior, we may draw a better operated and more accurate translating procedure for all translation workers and lovers.

There are several points that we must keep in mind. The definition of long and complex sentences mainly refers to three kinds of compounds; paralleling long sentence, which consists of two or more clauses with complete sentence structure and without affiliation; compound long sentence, which comprises a principle clause and some other sub-clauses like noun clauses, attributive clauses, adverbial clause, etc; and paralleling and compound long sentence, which as the name implies, the most complicated with the features of the previous two types of long sentences. The feature of long complex English sentences which includes many clauses, intricate grammar structure, and numerous propositional phrases. Reason analysis on the difficulties of long complex English sentences which proceeding from cultural factors, different language family, and different language style. Specifically, we have taken a concrete look on the contents of language disparity, covering from words translation, translation unit, sentence order, and translation of linking words. Also, we take a touch on the two different language structure, like the seven sentence structure pattern, Chinese grammar theory. Besides, some knowledge about translation theory is dispensable.

Then came to the most important part of translation procedure and translation methods. The author mostly appreciates the three steps of translation methods purposed by Nida. With the help of these advanced idea, the author successfully concluded a better one for all the English learners to refer.

\section{Acknowledgements}

To begin with, I would like to express my warmest thanks to Ms. Wang, for her inspiring guidance and encouragement throughout my research for this thesis, and also for her reading of the manuscript and helpful suggestions and all the support my thesis incurs.

I also greatly appreciate all my teachers and the library aid from Huazhong University of Science and Technology Wuchang Branch, supporting me through the stage of finding and checking material essentially necessary to the completion of this thesis for the Bachelor's degree.

Finally, I would also like to extend my heart-felt thanks to my parents and classmates for their support and blessing. Without their love and support, this thesis would never have been finished.

\section{References}

[1] Roger T. Bell. Translation and Translating: Theory and Practice [M].London: Longman Group UK ltd, 1991.

[2] Roman Jacobson. On Linguistic Aspects of Translation [M]. London: Macmillan, 1983.

[3] ADVANCED Learner's English-Chinese Dictionary [M]. London: Oxford University Press, 1986.

[4] Eugene A. Nida. Language and Culture Contexts in Translating [M]. Shanghai: Shanghai Foreign Language Education Press, 2003.

[5] Peter New mark. A Textbook of Translation [M]. London: Beijing University Press, 2001.

[6] Xu Jun, Zhong Weihe, He Qixin. An Introduction to Translation. [M]. Beijing: Foreign Language Education Press, 2009.

[7] Gentzler, mEdwin. Contemporary Translation Theories [M]. London: Routledge Inc, 1993.

[8] Shan Yizhen. Genaral English Grammar Course.[M]. Beijing: University of International Business and Economics Press, 2007.

[9] Jiang Junhu. Articles by classification breakthrough long difficult sentences in English [M]. Beijing: Beijing University of Aeronautics and Astronautics Press, 2010.

[10] Zhao Dexin. English Sentence Structure and Analysis [M]. Beijing: Foreign Language Education Press, 2007.

[11] Jiang Tao, Meng Fei.Breakthrough to Long English Sentences [M]. Beijing: Mechanical Industry Press, 2008.

[12] Yang Peng. Course to Complex English Sentences in GMAT\&GRE [M]. Beijing: Qunyan Press, 2010.

[13] Wang Bingxin.Cultural Translation Studies-Theory and Practice [M]. Tianjin: Nankai University Press, 2007.

[14] Gong Guangming. Science of Translation Thinking [M]. Shanghai: Shanghai Academy of Social Sciences Publishing House, 2004. 
[15] Liu Miqing. Contemporary Translation Theories [M]. Beijing: China Translation and Publishing Corporation, 1999.

[16] Mona Baker. In other words: A Course Book on Translation [M]. London: Routledge, 1992.

[17] Engine, Nida. Charles Taber. The Theory and Practice of Translation [M]. London: Hogarth Press, 1955
[18] SunWanbiao, Wang Enming. Advanced Course of Translation [M]. Shanghai: Shanghai Foreign Language Education Press, 2011.

[19] Munday J. Introducing Translation Studies: Theories and Applications. Beijing: Foreign Language Teaching and Research Press, 2014. 